\title{
Improvement in adhesion of diamond films on cemented WC substrate with $\mathrm{Ti}-\mathrm{Si}$ interlayers
}

\author{
Chii Ruey Lin *, Cheng Tzuo Kuo, Ruey Ming Chang \\ Institute of Materials Science and Engineering, National Chiao Tung University, 1001 Ta-Hsueh Road, Hsinchu 30050, Taiwan
}

Received 24 November 1997; accepted 4 May 1998

\begin{abstract}
Diamond films were deposited on the cemented $\mathrm{WC}+(3-5) \%$ Co substrates by a microwave plasma chemical vapor deposition system. The substrates were pretreated with various processing steps before diamond deposition, including: polishing, etching for Co removal, Ti coating by DC sputter, and amorphous Si coating by E-gun. The residual stress of the films was determined by both Raman shift and low incident beam angle X-ray diffraction (LIBAD) methods. The adhesion of the films was evaluated by indentation adhesion testing. The film morphology and film-substrate interface structure were examined by SEM and Auger electron spectroscopy, respectively. The results show that $\mathrm{Ti}-\mathrm{Si}$ can be a good interlayer to improve film adhesion and inhibit diffusion of Co to the substrate surface on diamond nucleation. This is due to the formation of strong $\mathrm{TiC}$ and $\mathrm{SiC}$ bonding to enhance film adhesion; $\mathrm{Si}$ acts as a promoter for diamond nucleation, and the residual stress with application of interlayer is much lower than that interlayer-free. The results also show the existence of an optimum Ti thickness for the best film adhesion. (C) 1998 Elsevier Science S.A. All rights reserved.
\end{abstract}

Keywords: Adhesion; Diamond films; Microwave plasma CVD; Stress

\section{Introduction}

Diamond is known to be the hardest and most wear resistant material in the world. Therefore, one of its applications is for use as a protective coating for cutting tools. However, the major problem with this application is the poor adhesion between the film and the substrate due to great internal stress in the films. The origins of the residual stress of diamond films are from the intrinsic stress due to the non-diamond content in the films and the thermal stress due to the difference in thermal expansion coefficients between the film and the substrate [1-4]. Another problem in diamond film deposition on the sintered cutting tools, such as cemented WC substrate, is that the typical binder, Co, for the tools is detrimental to diamond deposition [5-7]. Therefore, surface etching to minimize Co content on the substrate surface before diamond deposition is generally adopted.

The purpose of this study was to add $\mathrm{Ti}-\mathrm{Si}$ brazing alloy as an interlayer between the film and the substrate to minimize the thermal stress of the films and hopefully

\footnotetext{
* Corresponding author. Fax: +88602273 17191;

e-mail: crlin@ntut.edu.tw
}

develop a strong chemical bonding to increase the adhesion of the film.

\section{Experimental details}

Diamond film deposition on the interlayer-coated substrates was performed by a $5 \mathrm{~kW}$ microwave plasma enhanced chemical vapor deposition system. The substrate $[\mathrm{WC}+(3-5) \% \mathrm{Co}]$ was pretreated with the following processes before interlayer deposition: polishing with diamond paste; etching by $\mathrm{HF}: \mathrm{H}_{2} \mathrm{O}=1: 1$ solution to remove $\mathrm{Co}$ from the substrate surface; cleaning and drying. The pretreated substrate was then coated with a Ti interlayer by a DC sputtering system, and with a Si interlayer by an E-gun.

The residual stresses of the films were assessed by Raman spectroscopy and low incident beam angle X-ray diffraction (LIBAD) methods. In general, a material which is under tensile strain will exhibit a Raman peak which is shifted to lower frequency, while the Raman peak of a material undergoing a compressive strain is shifted to higher frequency. The Raman method was described in detail elsewhere [1]. As for the LIBAD 
method, the internal stress, $\sigma$, can be obtained from the following equation derived by Van Acker et al. in 1993 [8]:

$$
\begin{aligned}
\left(d-d_{\mathrm{o}}\right) / d_{\mathrm{o}}= & \sigma\left[1-\left(S_{2} / 2\right)\left(\cos ^{2} \psi\right) /\left(2 S_{1}+S_{2} / 2\right)\right] \\
& \times\left(2 S_{1}+S_{2} / 2\right)
\end{aligned}
$$

$\psi=\alpha-\theta$

where $S_{1}$ and $S_{2}$ are X-ray elastic constants; $d$ and $d_{\mathrm{o}}$ are the lattice plane spacing under stress and stress-free conditions, respectively; $\psi$ is the angle between the bisector of the incident and diffracted beam and the normal to the sample surface; $\alpha$ is the incident beam angle; and $\theta$ is the diffraction angle.

The adhesion of the films was determined by the indentation adhesion testing method, which was described in detail elsewhere [9]. The indentation load, $P$, versus the diameter of the cracked area, $X$, was recorded. The slope of the curve, $\mathrm{d} P / \mathrm{d} X$, is used as a measure of the quality of adherence between the film and the substrate. A greater value indicates a better adherence.

\section{Results and discussion}

\subsection{Effect of interlayer on film growth}

It is known that diamond growth depends on the deposition conditions, substrate material and its treatment. Therefore, it is expected that the application of an interlayer will have a great effect on film morphologies. Fig. 1a-c show the effect of three interlayer materials $(200 \mathrm{~nm}$ Ti only, $300 \mathrm{~nm}$ amorphous Si only, and $350 \mathrm{~nm} \mathrm{Ti}+300 \mathrm{~nm}$ amorphous $\mathrm{Si}$ ) on film morphologies, respectively. It indicates that the diamond quality for the film in Fig. 1a is the worst among them, and also shows a minimum diamond nucleation density at the same deposition time, as evidenced also by a broader non-diamond Raman peak around $1550 \mathrm{~cm}^{-1}$. Fig. $1 \mathrm{~b}$ shows the secondary nucleation phenomena. Therefore, in terms of uniformity in crystal size and diamond quality, Fig. 1c shows the best results. This may be due to the fact that $\mathrm{Ti}$ and $\mathrm{Si}$ are good carbide formers, giving strong chemical bonding between the film and the substrate, as can be evidenced from the XRD patterns of Fig. 2a,b. The crystalline $\mathrm{Si}$ has the same crystal structure as diamond crystal, so favors diamond nucleation, and it may be transformed from amorphous Si during the diamond deposition period.

\subsection{Effect of Ti thickness on residual stress of the films}

The major contributions to the residual stress in diamond films were investigated and found to be the thermal stress and intrinsic stress [1]. Therefore, a lower
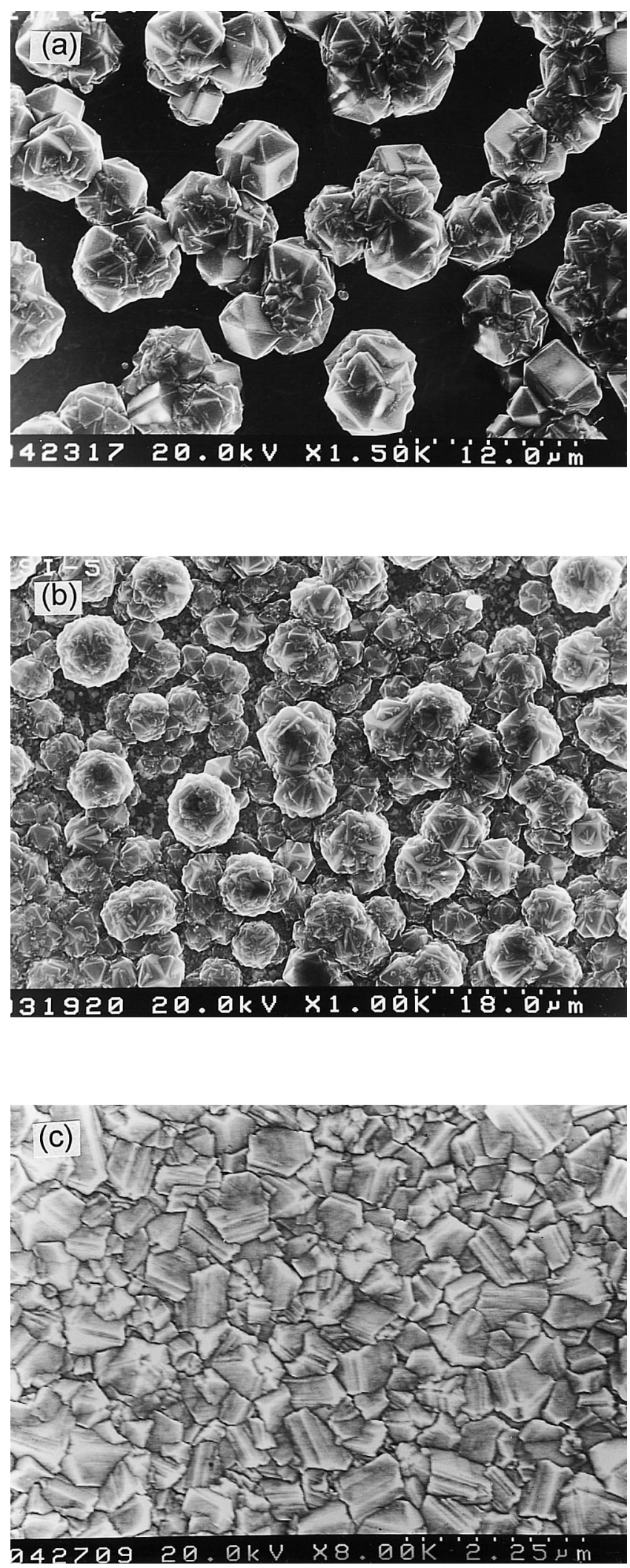

Fig. 1. Typical diamond film morphologies on WC substrate with three different interlayer materials: (a) $200 \mathrm{~nm} \mathrm{Ti}$; (b) $300 \mathrm{~nm}$ amorphous $\mathrm{Si}$; (c) $350 \mathrm{~nm} \mathrm{Ti}+300 \mathrm{~nm}$ amorphous $\mathrm{Si}$. 
(a)

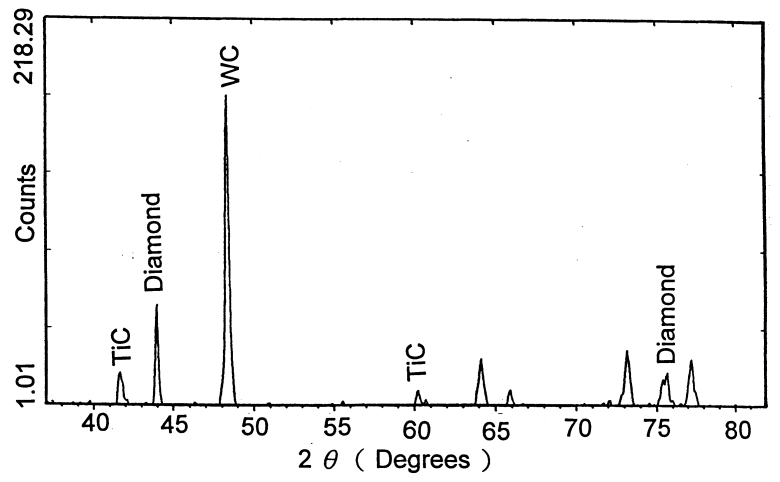

(b)

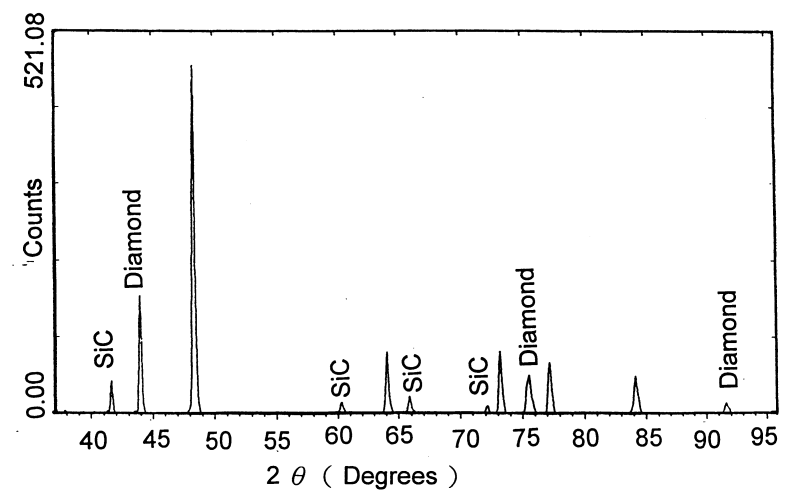

Fig. 2. Typical XRD patterns of diamond film through the interlayer coated before diamond film deposition: (a) $200 \mathrm{~nm} \mathrm{Ti}$; (b) $200 \mathrm{~nm} \mathrm{Si}$, individually.

deposition temperature, a better diamond crystal quality and a suitable interlayer application will favor a lower residual stress. The residual stresses for the films with $\mathrm{Ti}-\mathrm{Si}$ interlayer were estimated to range from -3.1 to $-2.7 \mathrm{GPa}$ by the Raman peak shift method, much lower than the values of -4.5 to $-4.1 \mathrm{GPa}$ for the films without interlayer. The negative sign indicates a compressive stress. The residual stress and Raman spectra at different Ti thickness are shown in Figs. 3 and 4, respectively. It reveals that the films with Ti thickness from 100 to $2800 \mathrm{~nm}$ do not make much difference to the residual stress.

The effects of Ti thickness on residual stress are also shown in Fig. 5, estimated from the X-ray peak shift of (311) diffraction by LIBAD, assuming X-ray elastic constants: $\quad S_{1}=-5.96 \times 10^{-5} \mathrm{GPa}^{-1}, S_{2}=1.86 \times$ $10^{-3} \mathrm{GPa}^{-1}$. Fig. 5 basically shows the same trend as Fig. 3. However, the stress values range from -6.8 to $-4.0 \mathrm{GPa}$, much greater than the values by the Raman shift method. This may be due to the fact that the penetration depth of the laser beam for generating the Raman signals is limited and localized, and the X-ray elastic constants used for stress calculations may not represent the real values for diamond films in this case.

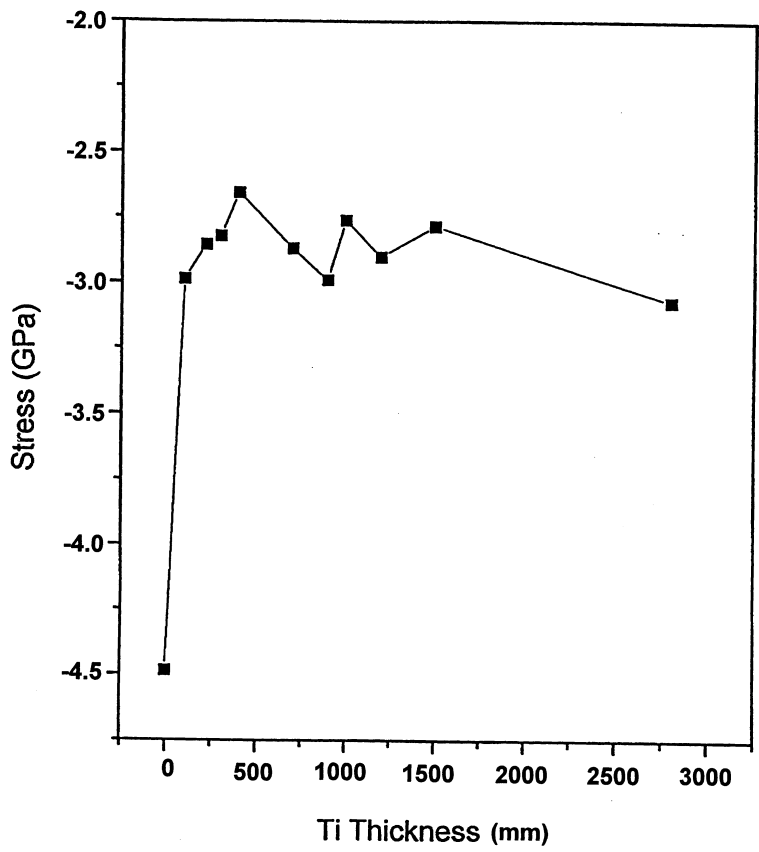

Fig. 3. Effect of Ti interlayer thickness on residual stress of diamond films ( $\mathrm{Si}=300 \mathrm{~nm}$ thickness, stress estimated by Raman shift method).

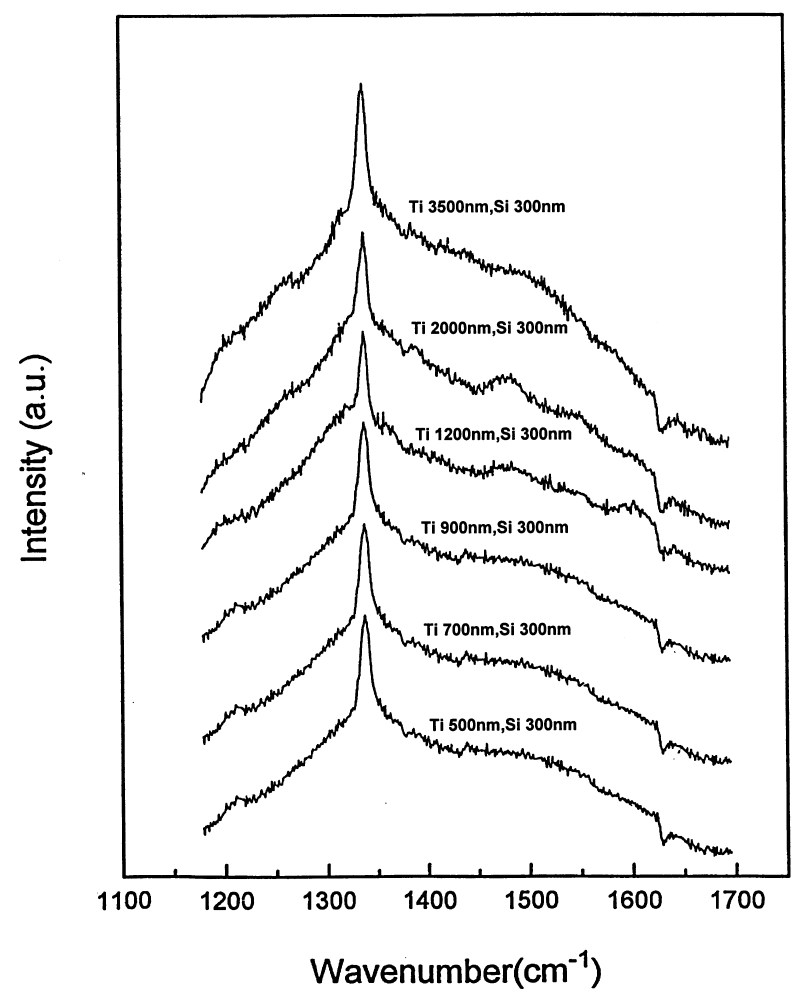

Fig. 4. Effect of Ti interlayer thickness on Raman peak patterns of diamond films ( $\mathrm{Si}=300 \mathrm{~nm}$ thickness).

\subsection{Effect of Ti thickness on adhesion of the films}

The traditional pull tests failed to measure the adhesion strength of the films with $\mathrm{Ti}-\mathrm{Si}$ interlayer due to a higher strength. Therefore, the indentation adhesion 


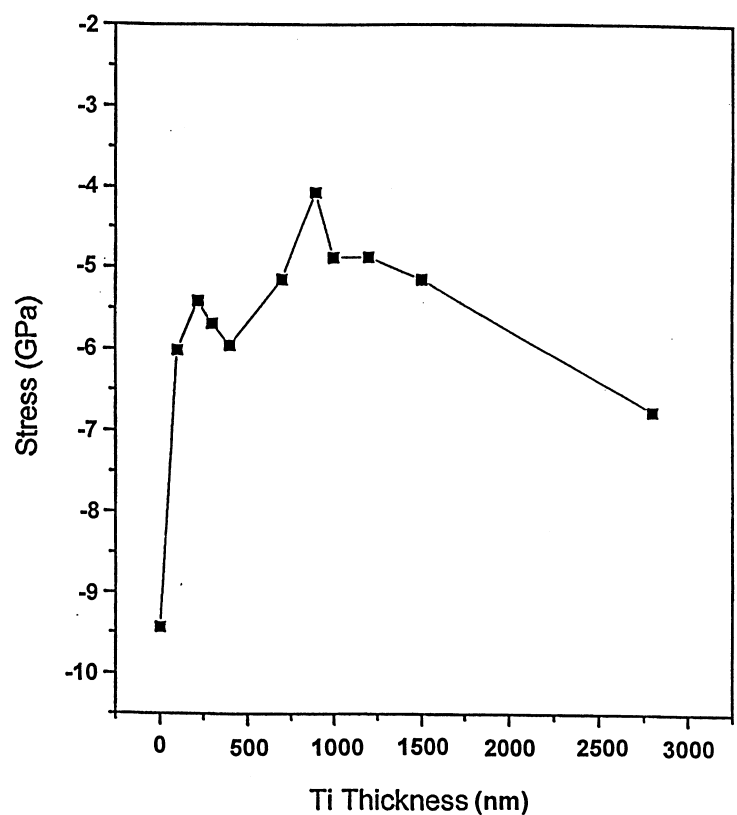

Fig. 5. Effect of Ti interlayer thickness on residual stress of diamond films $(\mathrm{Si}=300 \mathrm{~nm}$ thickness, stress estimated by X-ray diffraction method).

tests were adopted instead [10,11]. The indentation curves for diamond films with $\mathrm{Ti}-\mathrm{Si}$ interlayer at different Ti thickness are shown in Fig. 6. The slope of these curves, $\mathrm{d} P / \mathrm{d} X$, is a measure of the adherence of the films. The $\mathrm{d} P / \mathrm{d} X$ values range from 119 to

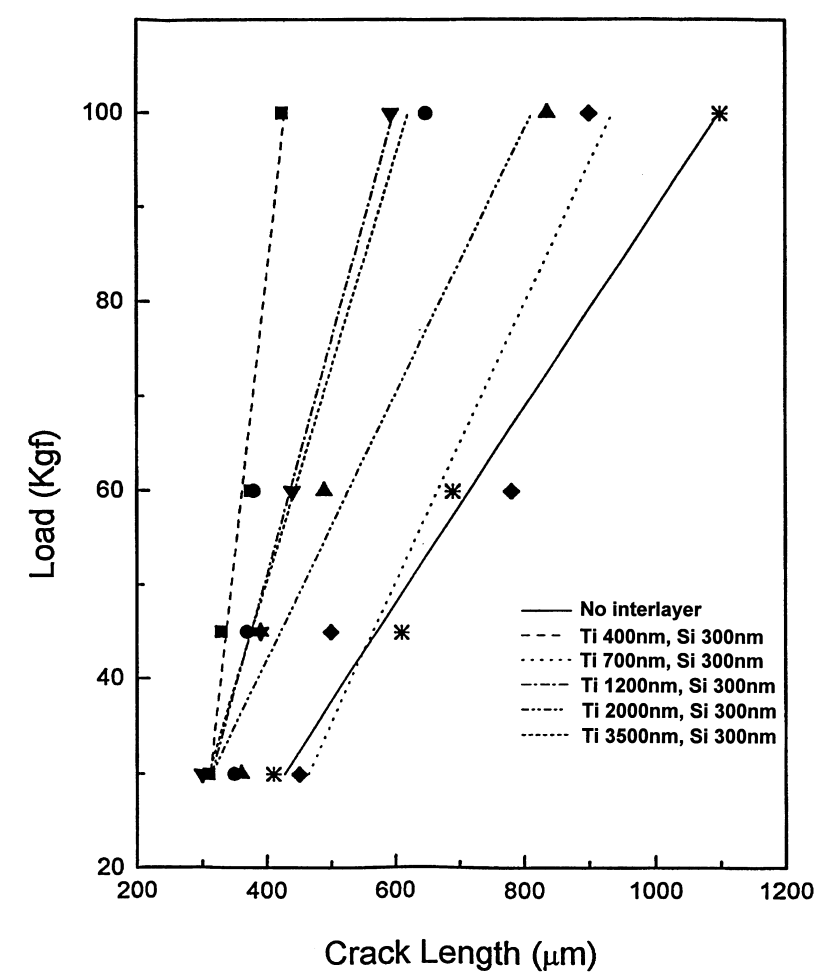

Fig. 6. Indentation load versus crack length curves for diamond films with different $\mathrm{Ti}-\mathrm{Si}$ interlayer.

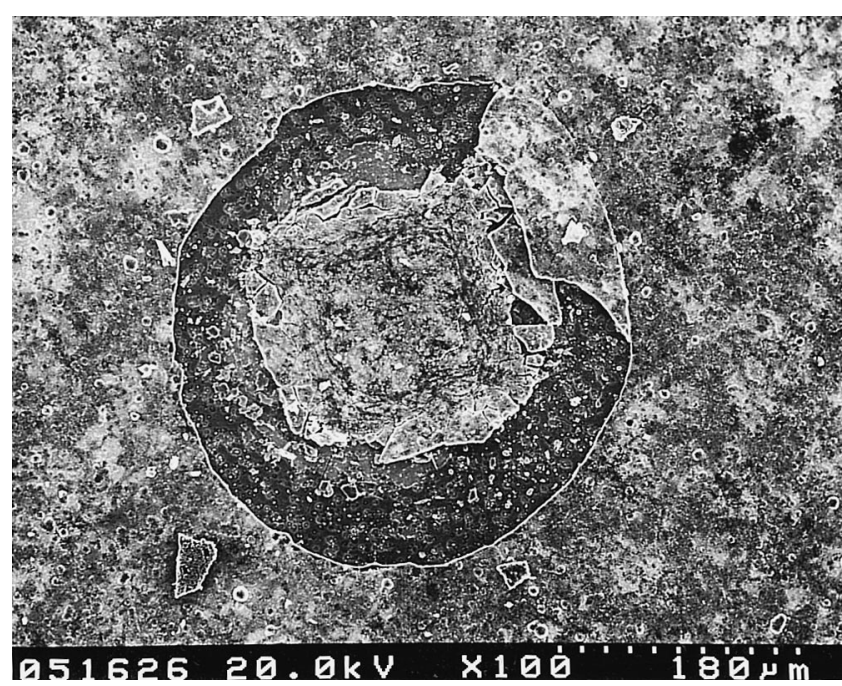

Fig. 7. Micrograph showing a mark on the films produced by indentation using a diamond indenter and a load of $1000 \mathrm{~N}(700 \mathrm{~nm} \mathrm{Ti}$; $300 \mathrm{~nm} \mathrm{Si}$ ).

$1101 \mathrm{kgf} / \mathrm{mm}$ for the films with Ti-Si interlayer, much greater than the $78 \mathrm{kgf} / \mathrm{mm}$ for the films without interlayer. The results also indicate the existence of an optimum Ti thickness for the best adherence. No crack induced by delamination occurred at the diamond films with Ti-Si interlayer up to a load of 1000 N. Fig. 7
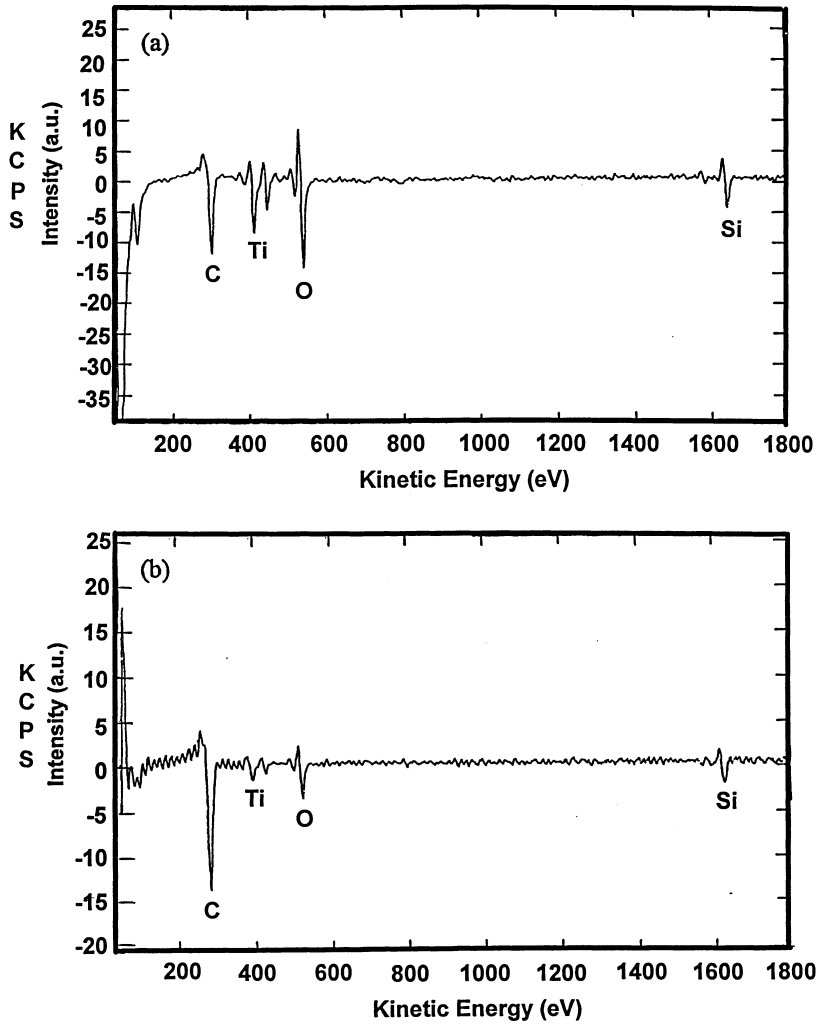

Fig. 8. Typical Auger spectra for a fractured diamond-coated WC substrate with $300 \mathrm{~nm} \mathrm{Ti}$ and $300 \mathrm{~nm} \mathrm{Si}$ : (a) on front surface of the substrate side; (b) on back surface of the diamond film. 
presents a SEM picture of the indented surfaces for an applied load of $1000 \mathrm{~N}$.

\subsection{Interface structure between diamond film and substrate}

The substrate side and the diamond film side of the fractured surface were examined by Auger electron spectroscopy. The results are shown in Fig. $8 \mathrm{a}$ and $8 \mathrm{~b}$, respectively. Both figures show obvious Ti and Si signals, but no Co signal. This signifies that the $\mathrm{Ti}+\mathrm{Si}$ interlayer can effectively inhibit diffusion of Co to the substrate surface on diamond nucleation. The carbon signal of the substrate side and part of the areas of the back side of the diamond film are identified to be graphite, but the carbon signal for the particles on the back side of the fractured films is graphite + carbide, as compared with the detailed patterns of carbon signals in ref. [12]. The results are in agreement with the statement that $\mathrm{Ti}$ and $\mathrm{Si}$ may form strong $\mathrm{TiC}$ and $\mathrm{SiC}$ bonding to enhance the film adherence.

\section{Conclusions}

Diamond films were deposited on the cemented $\mathrm{WC}+(3-5 \%)$ Co substrates, which were pretreated with various processing steps including: polishing, etching, Ti coating and amorphous Si coating. The experimental results show the following conclusions.

(1) $\mathrm{Ti}+\mathrm{Si}$ can be a good bonding material used as an interlayer to improve the adhesion between the diamond film and the substrate. This is due to the formation of strong $\mathrm{TiC}$ and $\mathrm{SiC}$ bonding to enhance the film adherence, the Si layer can act to promote diamond nucleation, and the residual stress with application of interlayer is much lower than that interlayer-free.

(2) Within the present $\mathrm{Ti}$ thickness conditions $(100-2800 \mathrm{~nm})$, the Ti thickness has no significant effect on the residual stress, but there exists an optimum Ti thickness for the best adhesion.

\section{Acknowledgement}

This work was supported by the National Science Council of Taiwan under Contract No. NSC86-2221-E009-041. We would also like to thank Professor K.H. Chen of Academia Sinica in Taipei, and Professor Y.Z. Hsieh of NCTU in Hsinchu for the use of their Raman spectroscopes. Professor I.-Nan Lin of NTHU at Hsinchu is gratefully acknowledged for his assistance.

\section{References}

[1] C.T. Kuo, C.R. Lin, H.M. Lien, Thin Solid Films 290291 (1996) 254

[2] J.F. Denatale, J.F. Flintoff, A.B. Harker, J. Mater. Sci. 27 (1992) 553

[3] G. Gille, B. Rau, Thin Solid Films 120 (1984) 109.

[4] H. Windischmann, G.F. Epps, J. Appl. Phys. 69 (4) (1991) 2231.

[5] T.H. Huang, C.T. Kuo, C.S. Chang, C.T. Kao, H.Y. Wen, Diamond Relat. Mater. 1 (1992) 594.

[6] X.C. He, Z.M. Zhang, H.S. Shen, G.Y. Li, Diamond Relat. Mater. 5 (1) (1996) 83.

[7] J.L. Chen, T.H. Huang, F.M. Pan, C.T. Kuo, C.S. Chung, T.S. Lin, Surf. Coat. Technol. 5455 (1992) 392.

[8] K. Van Acker, H. Mohrbacher, B. Blanpain, P. Van Houtte, J.P. Celis, Mater. Res. Soc. Symp. Proc. 308 (1993) 677.

[9] C.T. Kuo, T.Y. Yen, T.H. Huang, J. Mater. Res. 5 (1990) 2515.

[10] M.D. Drory, J.W. Hutchinson, Science 263 (1994) 1753.

[11] P.C. Jindal, D.T. Quinto, G.J. Wolfe, Thin Solid Films 154 (1978) 361

[12] B.E. Williams, J.T. Glass, J. Mater. Res. 4 (1989) 373. 